\title{
Cytogenetic insights into Festulolium
}

\author{
J. MAJKA ${ }^{1,2 *}$, M. MAJKA ${ }^{1,2}$, D. KOPECKÝ ${ }^{1}$, and J. DOLEŽEL ${ }^{1}$ \\ Czech Academy of Sciences, Institute of Experimental Botany, Centre of the Region Hana for Biotechnological \\ and Agricultural Research, CZ-77900 Olomouc, Czech Republic ${ }^{1}$ \\ Institute of Plant Genetics, Polish Academy of Sciences, PL-60479 Poznan, Poland ${ }^{2}$
}

\begin{abstract}
Climate change calls for new methods and plant materials to breed crops adapted to new environmental conditions. Sustainable forage and amenity grass production during periods of severe drought and heat waves during summer, and unequal distribution of precipitation over the year will require drought-tolerant genotypes. However, high-yielding ryegrasses (Lolium spp.), which are the most commonly used grass species, suffer during abiotic stresses. Introgression of drought and heat tolerance from closely related fescues (Festuca spp.) offers an opportunity to develop superior hybrid cultivars to mitigate the negative impact of climate change. Intergeneric cross-hybridization and the development of Festulolium (Festuca $\times$ Lolium) hybrids was initiated 100 years ago and resulted in registration of almost one hundred cultivars. For a long time, their genome composition was not known and was debated by breeders and geneticists. In the last three decades, molecular cytogenetic and genomic approaches have enabled their detailed characterization. These studies revealed a gradual replacement of Festuca chromosomes by those of Lolium in consecutive generations leading to an almost complete elimination of Festuca chromatin in the introgression forms. On the other hand, amphiploid cultivars seem to be more stable with the optimal proportions of the Lolium to Festuca genomes at about 2:1. In this mini review, we discuss recent advances in the analysis of the genome composition of Festulolium hybrids with a specific focus on genome (in)stability.
\end{abstract}

Additional key words: chromosome pairing, Festuca spp., genome balance, genome composition, Lolium spp.

\section{Introduction}

Grasslands are one of the largest ecosystems in the world covering about one-third of the Earth's terrestrial surface and comprising $80 \%$ of the agriculturally productive land (Boval and Dixon 2012). Grasses (Poaceae), a family of monocotyledonous plants, encompass cereals, turf, and pasture grasses, and other economical species such as bamboos and energy grass Miscanthus. They are adapted to a full range of environmental conditions, spanning from hot equatorial areas to the coldest regions towards the poles, and from deserts to aquatic habitats. They play an essential role in agriculture, being a major staple for animal diets, and also provide valuable ecosystem services. Grasses reduce water runoff (Macleod et al. 2007), stabilize the soil profile and prevent soil erosion. They also have an aesthetic role and serve as ground cover for cultural and recreational needs such as sport and amenity lawns.

Recently, cultivation of grasses is heavily impacted by the climate change. The last four years were the hottest on record and severe drought periods are more frequent (Trnka et al. 2013, Zahradnicek et al. 2015). Models of future climate predict continuing change in the next few years with a higher frequency of dry and hot periods during summers and more uneven distribution of precipitation over the year (UN Climate Action Summit 2019). Climate change affects humans globally and in response, new market requirements have emerged, especially in agriculture. To mitigate the impact of climate change and to meet new demands, it is necessary to incorporate new strategies into plant breeding to develop new cultivars suitable for future use.

The gene pool of each species has its limits of genetic variation, and this variation is regularly narrowed down

Submitted 9 June 2020, last revision 18 June 2020, accepted 20 June 2020.

Abbreviations: GISH - genomic in situ hybridization.

Acknowledgments: This research was funded by the Czech Science Foundation (grant award 20-10019S) and by the European Regional Development Fund OPVVV project "Plants as a tool for sustainable development" number CZ.02.1.01/0.0/0.0/16_019/0000827 supporting Excellent Research at CRH. MM has been supported by the Foundation for Polish Science.

* Corresponding author: e-mails: majkaj@ueb.cas.cz,jcho@igr.poznan.pl 
even further during cultivar development. Thus, widening of the gene pool and introgression of genes underlying beneficial traits seem a prerequisite for breeding progress and development of cultivars with the ability to withstand future climatic conditions. One of the approaches already applied with considerable success is interspecific (wide) hybridization.

\section{Interspecific hybridization}

Interspecific hybridization, frequently accompanied by whole genome duplication (process called allopolyploidization) refers to mating of individuals from different species. Allopolyploidization is widespread in nature and has been an important force in plant evolution and speciation (Soltis and Soltis 2009). Many economically important species are allopolyploids, including wheat, rapeseed, cotton, and banana (Morgan et al. 2011). Besides these ancient allopolyploids, which have originated thousands of years ago, recent and ongoing natural interspecific hybridization and allopolyploidization events are known, including Tragopogon and Senecio (Hegarty and Hiscock 2009).

Interspecific hybridization has been used in plant breeding with various aims: 1) merging of entire genomes of parental species to combine their desirable traits (amphiploid forms), 2) merging of entire genomes of parental species to broaden the gene pools, and 3) introgressions of desirable trait/traits from one (frequently wild) species into elite cultivars of another species (introgression forms). One of the most successful interspecific hybrids synthetically developed is Triticale, a hybrid of wheat (Triticum) and rye (Secale). It combines high yielding property of wheat with the ability to grow in harsher conditions due to abiotic stress tolerance inherited from rye (Arseniuk 2015). Similarly, several agronomically important traits have been transferred from wild relatives into cultivars by wide hybridization such as the soft grain endosperm structure from Aegilops speltoides into bread wheat (Pshenichnikova et al. 2010), black rot resistance from Brassica carinata into cauliflower (Sharma et al. 2017), and leaf rust resistance from Aegilops tauschii to triticale (Majka et al. 2018).

\section{Festulolium cultivars}

The wide hybridization approach has also been used in the forage grass breeding. Festulolium hybrids obtained by crossing Festuca ssp. (fescues) with Lolium spp. (ryegrasses), combine complementary agronomic attributes of the parental species. Ryegrasses are important fodder crops with high seed yield, excel in digestibility and palatability and show highly desirable rapid and intensive spring growth. Fescues, on the other hand, provide traits associated with abiotic and biotic stress tolerance, such as drought tolerance, freezing tolerance, winter hardiness, and resistance to fungal diseases (Thomas and Humphreys 1991, Jauhar 1993, Płażek et al. 2018). To date, 78 Festulolium cultivars have been released worldwide - 33 developed by the amphiploid breeding and 45 resulting from the introgression breeding (Humphreys and Zwierzykowski 2020). Amphiploid cultivars are developed by intermating of $F_{1}$ hybrids followed by selection of hybrids with about equal proportions of parental chromatin. On the other hand, introgression cultivars originate from an interspecific $F_{1}$ hybrid (frequently created from parents of different ploidy), followed by one or more backcrosses to one of the parents. This results in the forms morphologically close to recurrent parent, but with one or a few improved characteristics introgressed from the other species.

Festulolium cultivars are produced from diverse intergeneric hybrids. The most common cross combinations are L. muliflorum $\times F$. pratensis (amphiploid forms) and L. muliflorum $\times F$. arundinacea (introgression forms; Humphreys and Zwierzykowski 2020). However, a recent need for drought tolerance in new cultivars calls for the introduction of different species into the mating schemes. According to Černoch and Kopecký (2020), $F$. glaucescens and $F$. mairei are the most promising fescue species for initial hybridization with ryegrasses and the development of resilient Festulolium cultivars. Mating in such combinations has already been initiated at IBERS (Institute of Biological, Environmental and Rural Sciences, Aberystwyth) and DLF Seeds \& Science (Humphreys and Zwierzykowski 2020, V. Černoch, personal communication).

For a long time, the genetic constitution of many Festulolium hybrids remained unknown. Only the availability of molecular methods provided tools for comprehensive investigation of the genome composition of hybrids at either chromosomal, or DNA levels (Thomas et al. 1994, Kopecký et al. 2011). Festulolium hybrids show a unique combination of two features: 1) the similarity between parental Festuca and Lolium chromosomes at the DNA sequence allows for their pairing in meiosis (homoeologous pairing), and, on the other hand, 2) repetitive elements of the two parental species diversified enough for unambiguous identification of the Festuca and Lolium chromosomes in hybrids by the genomic in situ hybridization (GISH) (Fig. 1). Combination of GISH with high-throughput genotyping, e.g., using diversity arrays technology and single nucleotide polymorphism platforms, provides an invaluable tool for tracking genome structure and evolution during the development of new cultivars and for the protection of existing cultivars.

\section{Homoeologous chromosome pairing and recombination}

It is a general feature of wide hybrids that chromosomes from the parental species (homoeologues) do not pair and recombine in meiosis. The absence of homoeologous chromosome pairing can be a consequence of the DNA sequence dissimilarity or the presence of a genetic system(s) that prevent such pairing. Several meiotic regulators have been identified in allopolyploids including $P h 1$ (pairing homoeologous 1) in wheat (Riley and Chapman 1958, 


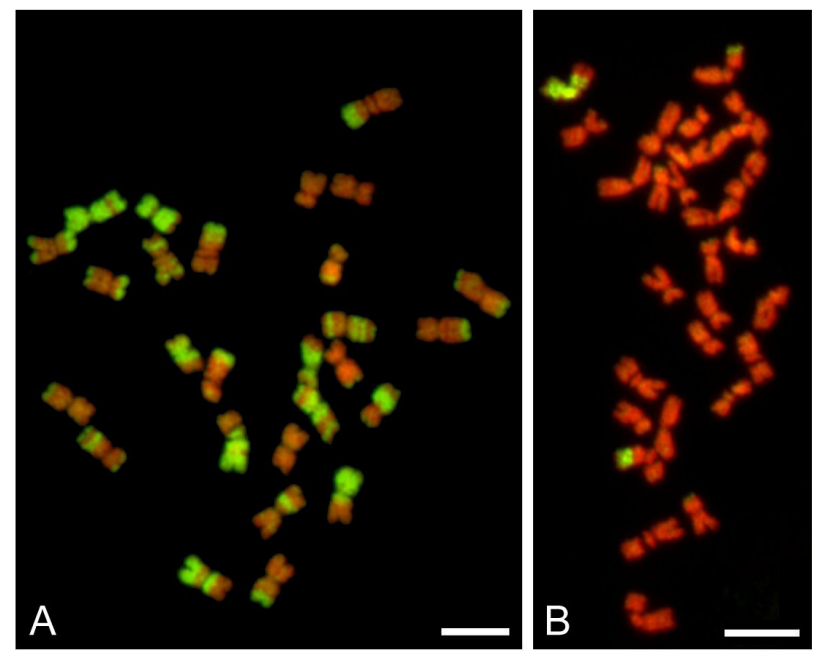

Fig. 1. The genomic constitution of the amphiploid form (cv. Paulita, $A$ ) and introgression form (cv. Lofa, $B$ ) of Festulolium. The genomic DNA of Festuca (green fluorescence), chromatin of Lolium was counterstained with propidium iodide (red fluorescence). Scale bars are $5 \mu \mathrm{m}$. (Photo: D. Kopecký).

Sears and Okamoto 1958) and $\operatorname{PrBn}$ (pairing regulator in Brassica napus) in rapeseed (Jenczewski et al. 2003). There are exceptions to the no-pairing rule in wide hybrids, several such hybrids have been identified where homoeologous chromosome pairing does occur, such as Allium and Lilium hybrids (Van Heusden et al. 2000, Khan et al. 2009). Similarly, promiscuous pairing of the Festuca and Lolium chromosomes has been observed in Festulolium hybrids, indicating high pairing affinity and interchangeability of homoeologous chromosomes from these two genera, and the absence of a meiotic regulator (Humphreys and Pasakinskiene 1996, Zwierzykowski et al. 1998). This feature does lead to extensive meiotic recombination and enormous genetic variability among the progeny, but also to their genomic instability.

Compared to other wide hybrids in plants, the frequency of homoeologous chromosome pairing and recombination in Festulolium is extraordinarily high and in some combinations almost reaches the level of homologous pairing. The actual frequency differs among hybrid combinations. Zwierzykowski et al. (2008) observed 9:1 ratio of homologous $v s$. homoeologous pairing in tetraploid $F$. pratensis $\times L$. perenne hybrids. In $L$. multiflorum $(\mathrm{Lm}) \times F$. glaucescens $(\mathrm{Fg})$ hybrids, 8.54 paired Lm-Lm arms, 7.83 Fg-Fg arms and 4.09 associations between homoeologous Lm-Fg arms were observed (Kopecký et al. 2009), similarly to the results of Morgan et al. (2001), who reported the 5:1 ratio. Detailed analysis of tetraploid $\mathrm{F}_{1}$ hybrid of $L$. multiflorum $\times F$. arundinacea indicated a possible association between the phylogenetic distance separating the parents and the frequency of homoeologous chromosome pairing (Kopecký et al. 2009).

The extent of homoeologous chromosome pairing seems to be affected by the proportion of the total numbers of chromosomes from both parents and by competition for pairing partners. Kopecký et al. (2008) studied the frequency of homoeologous chromosome pairing in monosomic and disomic substitution lines of $F$. pratensis chromosome(s) in tetraploid L. multiflorum and found that the observed frequency of homoeologous pairing was slightly lower than random in disomic lines (where two $F$. pratensis and two L. multiflorum chromosomes were present in each orthologous group) suggesting a slight preference for homologous pairing. On the other hand, perfectly normal pairing of homoeologues was observed in monosomic lines (where only a single $F$. pratensis chromosome was present).

Frequent homoeologous chromosome pairing in Festulolium leads to extensive recombination of the parental genomes via intergeneric chromosome translocations (Thomas et al. 1994, Pasakinskiene et al. 1997, Humphreys et al. 1998). The translocation breakpoints in the recombined Festuca-Lolium chromosomes are fairly evenly distributed along the chromosome arms, from the centromere to the telomeres, but with infrequent recombination at the most distal and proximal regions (Zwierzykowski et al. 1998, 1999). Accordingly, Kopecký et al. (2010) reported the highest frequency of homoeologous recombination in the interstitial to distal parts of the chromosomes. Recombination cold spots (regions with decreased frequency of recombination) were found in the pericentromeric and centromeric regions, and also in the subtelomeric and telomeric regions (the most distal segments representing $10 \%$ of the chromosome length) (Kopecký et al. 2010). It is worth noting that both parental species of the analyzed hybrids, i.e., L. multiflorum, F. arundinacea, and F. pratensis are known to have localized distal chiasmata (Rees and Dale 1974, Karp and Jones 1983) so in hybrids, the patterns of crossing over change quite drastically.

A high level of homoeologous pairing may suggest that a meiotic regulator such as the wheat $P h 1$ is not present in Festulolium hybrids. This may not be entirely true. Jauhar (1975) concluded that $F$. arundinacea possesses a diploidlike pairing regulator. Subsequently, this regulator was identified in all broad-leaved fescues of the Schedonorus subgenus (Jauhar 1975, 1993, Kopecky et al. 2009). The system, however, differs from the $P h 1$, it is hemizygousineffective, or haplo-insufficient (Jauhar 1993). As hemizygous-ineffective it is non-functional in the $\mathrm{F}_{1}$ hybrids, such as Lolium $\times F$. arundinacea. This haploinsufficiency hampers its direct utilization in stabilization of hybrid genomes and one may expect reactivation of its function only after the locus doubling. The origin of this system remains unknown. However, Kopecký et al. (2009) showed that F. arundinacea inherited it from $F$. glaucescens, one of its progenitor, rather than from $F$. pratensis, the other progenitor.

\section{Genome balance and stability of hybrids}

In general, the fertility of allopolyploids relies on regular meiosis, and meiotic irregularities, such as multivalent formation, reduce fertility and may lead to complete sterility. This is not an issue in Festulolium. Despite the 
formation of quadrivalents and meiotic irregularities leading to frequent aneuploidy (up to $80 \%$ in cvs. Hostýn and Perseus), fertility is high and seed set is sufficient for commercial production (Ghesquiere et al. 2010, Kopecký et al. 2017).

Another issue affecting the extent of use of Festulolium in the grass business is the stability of hybrid genomes and the potential for the elimination of chromatin of one of the species in consecutive generations of sexual reproduction. It has been observed that the Lolium chromatin prevails in the Festulolium hybrids (Zwierzykowski et al. 1998, 2006, 2011, Kopecký et al. 2006, 2019, Książczyk et al. 2015, Majka et al. 2018a, 2019). Zwierzykowski et al. (2006, 2011) observed slow and gradual replacement of the Festuca chromosomes by those of Lolium in consecutive generations of $F$. pratensis $\times L$. perenne hybrids (Fig. 2). As this was observed in breeding materials, it was not entirely clear if the gradual elimination of the Festuca was a natural or a selection-induced process. A comparison of unselected and selected $\mathrm{F}_{2}-\mathrm{F}_{4}$ progenies of $F$. pratensis $\times$ L. perenne verified process as natural and independed of selection, suggesting the dominance of the Lolium chromatin over that of Festuca (Zwierzykowski et al. 2012). Similarly, J. Majka et al. (2018) observed a decreasing number of Festuca chromosomes across the $\mathrm{F}_{2}-\mathrm{F}_{9}$ generations of $F$. pratensis $(4 x) \times L$. perenne $(4 x)$ together with increasing proportion of rearranged Festuca chromosomes (with translocated Lolium segment). Interestingly, Majka et al. (2019) observed no preference in the transmission of either Festuca or Lolium alleles to the subsequent generations of $F$. pratensis $\times L$. perenne hybrid using inter-simple sequence repeat (ISSR) markers. However, that results might have been compromised by the dominant character of the ISSR markers. Similarly, all amphiploid Festulolium cultivars analyzed to date show a higher number of chromosomes of Lolium origin compared to those from Festuca (Zwierzykowski et al. 1998, Kopecký et al. 2005, 2006).

Genome composition of Festulolium seems to reflect the phylogenetic relationship of the parental species. Thus,

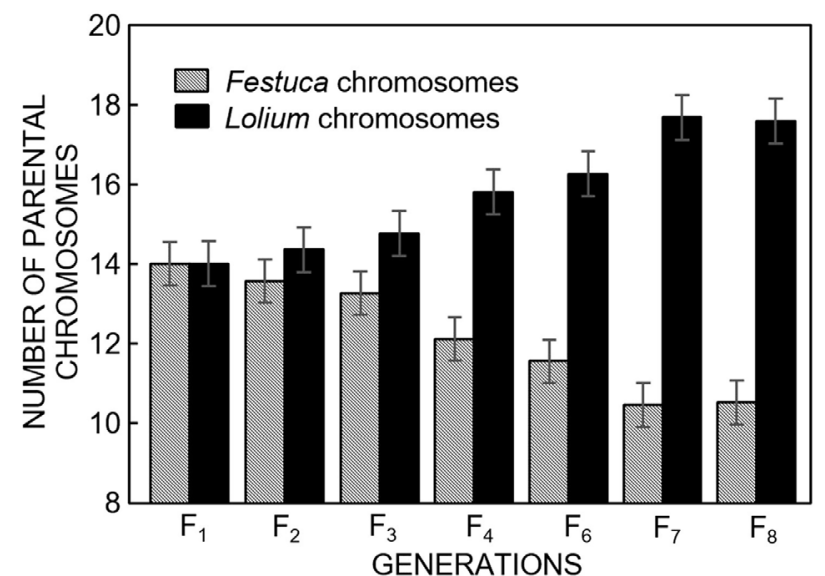

Fig. 2. Genome dominance in subsequent generations of Festuca pratensis $\times$ Lolium perenne. Means \pm SEs (adopted from Zwierzykowski et al. 2006, 2011). cv. Lueur developed from a L. multiflorum $\times$ F. glaucescens hybrid had fewer recombined chromosomes than cultivars developed from $L$. multiflorum $\times F$. pratensis hybrids (Kopecký et al. 2006). One of the possible explanations is that of a closer relationship of L. multiflorum to $F$. pratensis than to $F$. glaucescens. Differences in the genome composition can also mirror different breeding strategies. Closely related cvs. Perun and Perseus (L. multiflorum $\times$ $F$. pratensis) differ in their genome compositions, which is consistent with their breeding history. Perun is the oldest Czech L. multiflorum $\times F$. pratensis cultivar with more equal proportion of the parental genomes. On the contrary, Perseus was developed by selection of plants from Perun, primarily for use in Western Europe and with high seed yield, late heading date, and high dry-matter yield. Thus, its genome composition with a higher proportion of the Lolium chromatin can be expected (Kopecký et al. 2017). Cv. Spring Green has the lowest proportion of the Festuca chromatin among all amphiploid cultivars of $L$. multiflorum $\times F$. pratensis. It was developed from intercross of cvs. Kemal, Elmet, Prior, and Tandem, and the small amount of Festuca chromatin could be a consequence of the fact that cv. Kemal does not carry any Festuca chromatin detectable by GISH (Kopecký et al. 2006).

Genome stability differs between amphiploid and introgression cultivars of Festulolium (Kopecký et al. 2019). While amphiploids display relatively stable genome composition and no further shifts towards Lolium genome, elimination of introgressed segment(s) has been observed in the introgression forms. Stabilization of the hybrid genome in amphiploid cultivars is observed at about 2:1 proportion of Lolium vs. Festuca chromosomes (Kopecký et al. 2017). This ratio probably creates optimal combinations of parental alleles and the highest heterosis. On the other hand, introgression cultivars appear to be highly unstable and a reversion to the parental (Lolium) forms may be completed even within four generations of multiplication, unless the introgressed segment confers a strong selective advantage (Kopecký et al. 2019). In some cultivars, the Festuca chromatin was not detected in any individual analyzed (Kopecký et al. 2006).

Importantly, the rate of elimination of Festuca chromatin is different for different chromosomes. King et al. (2013) estimated the transmission rates of parental chromosomes in consecutive generations of seven monosomic substitution lines developed from hybrids between Lolium perenne and Festuca pratensis. They found a much higher transmission of complete Lolium chromosomes compared to complete Festuca chromosomes in the successive generation after the backcross of diploid monosomic substitution lines of L. perenne $\times F$. pratensis $(13 \mathrm{~L}+1 \mathrm{~F}$, the proportion was $89: 11$, instead of expected $1: 1$ ) to Lolium parent. Unfortunately, the authors did not indicate the parental origin of the translocated chromosomes and therefore, the overall Festuca chromatin elimination could not be assessed from their study. However, chromosomes $2 \mathrm{~F}, 4 \mathrm{~F}, 5 \mathrm{~F}$, and $6 \mathrm{~F}$ were eliminated more frequently than the remaining three Festuca chromosomes. Similarly, Kopecký et al. (2019) found that chromosome 5F 
was eliminated more frequently than other Festuca chromosomes in tetraploid monosomic L. multiflorum $\times$ $F$. pratensis substitution lines.

From the breeder's point of view, the mode of operation of the mechanisms causing shift in genome composition is far from a trivial detail, as it determines the ease of transfer of a chromosome segment with the trait of interest to the progeny and its proper transmission to subsequent generations.

\section{Conclusions}

Growing number of new Festulolium cultivars as well as the interest among growers demonstrate that Festulolium has become an integral part of the grass industry. Festulolium cultivars are grown throughout the world and their role and diversification of their uses will likely keep expanding along with the global climate change impacts. We envisage three main tasks for the future Festulolium research and breeding: 1) development of a platform for high-throughput and cheap determination of genome composition, cultivar identification, and legal protection to replace the time-consuming and labourious GISH method, and the costly (per plant, not per datapoint) DArTseq method, 2) finding appropriate combinations of parental species and proper genome balance between Festuca and Lolium for different climatic conditions to increase the potential of Festulolium, and 3) identification of the chromosome pairing regulator in polyploid fescues as a prerequisite to develop new and stable Festulolium cultivars with fescue-derived tolerance to abiotic stresses. A close collaboration between the research and breeding should secure a rapid integration of the new knowledge into breeding programs to mitigate the impact of climate change by developing resilient and high-yielding Festulolium cultivars.

\section{References}

Arseniuk, E.: Triticale abiotic stress - an overview. - In: Eudes, F. (ed.): Triticale. Pp. 69-81. Springer, Cham 2015.

Boval, M, Dixon, R.M.: The importance of grasslands for animal production and other functions: a review on management and methodological progress in the tropics. - Animal 6: 748-762, 2012.

Cernoch, V., Kopecky, D.: Drought tolerance and regrowth capacity revealed in the Festuca-Lolium complex - Biol. Plant. 64: 561-568, 2020.

Ghesquière, M., Humphreys, M.W., Zwierzykowski, Z.: Festulolium. - In: Boller, B., Posselt, U.K., Veronesi, F. (ed.): Handbook of Plant Breeding Vol. 5 Fodder crops and amenity grasses. Pp. 293-316. Springer, Dordrecht 2010.

Hegarty, M.J., Hiscock, S.J.: The complex nature of allopolyploid plant genomes. - Heredity 103: 100-101, 2009.

Humphreys, M.W., Pasakinskiene, I.: Chromosome painting to locate genes for drought resistance transferred from Festuca arundinacea into Lolium multiflorum. - Heredity 77: 530534,1996.

Humphreys, M.W., Zare, A.G., Pasakinskiene, I., Thomas, H., Rogers, W.J., Collin, H.A.: Interspecific genomic rearrangements in androgenic plants derived from Lolium multiflorum $\times$ Festuca arundinacea $(2 n=5 x=35)$. - Heredity 80: 78-82, 1998.

Humphreys, M.W., Zwierzykowski, Z.: Festulolium, a century of research and breeding and its increased relevance in meeting the requirements for multiplication grassland agriculture. Biol. Plant. 64: 578-590, 2020.

Jauhar, P.P.: Chromosome relationships between Lolium and Festuca (Gramineae). - Chromosoma 52: 103-121, 1975.

Jauhar, P.P. Cytogenetics of the Festuca-Lolium Complex, Relevance to Breeding. (Monographs on Theoretical and Applied Genetics 18) - Springer, Berlin - Heidelberg - New York 1993.

Jenczewski, E., Eber, F., Grimaud, A., Huet, S., Lucas, M.O., Monod, H., Chevre, A.: PrBn, a major gene controlling homeologous pairing in oilseed rape (Brassica napus) haploids. - Genetics 164: 645-653, 2003.

Karp, A., Jones, R.N.: Cytogenetics of Lolium perenne. Part 2: Chiasma distribution in inbred lines. - Theor. appl. Genet. 64: 137-145, 1983.

Khan, N., Barba-Gonzalez, R., Ramanna, M.S., Visser, R.G.F., Van Tuyl, J.M.: Construction of chromosomal recombination maps of three genomes of lilies (Lilium) based on GISH analysis. - Genome 52: 238-251, 2009.

King, J., Armstead, I., Harper, J., King, I.: Transmission frequencies of introgressed Festuca pratensis chromosomes and chromosome segments in Lolium perenne. - Crop Sci. 53: 1968-1973, 2013.

Kopecký, D., Bartoš, J., Christelová, P., Černoch, V., Kilian, A., Doležel, J.: Genomic constitution of Festuca $\times$ Lolium hybrids revealed by the DArTFest array. - Theor. appl. Genet 122: 355-363, 2011.

Kopecký, D., Bartoš, J., Zwierzykowski, Z., Doležel, J.: Chromosome pairing of individual genomes in tall fescue (Festuca arundinacea Schreb.), its progenitors, and hybrids with Italian ryegrass (Lolium multiflorum Lam.). - Cytogenet. Genome Res. 124: 170-178, 2009.

Kopecký, D., Havránková, M., Loureiro, J., Castro, S., Lukaszewski, A.J., Bartoš, J., Kopecká, J., Doležel, J.: Physical distribution of homoeologous recombination in individual chromosomes of Festuca pratensis in Lolium multiflorum. - Cytogenet. Genome Res. 129: 162-172, 2010.

Kopecký, D., Horáková, L., Duchoslav, M., Doležel J.: Selective elimination of parental chromatin from introgression cultivars of $\times$ Festulolium $($ Festuca $\times$ Lolium $)$. - Sustainability 11: 3153, 2019.

Kopecký, D., Loureiro, J., Zwierzykowski, Z., Ghesquiere, M., Dolezel, J. Genome constitution and evolution in Lolium $\times$ Festuca hybrid cultivars (Festulolium). - Theor. appl. Genet 113: 731-742, 2006.

Kopecký, D., Lukaszewski, A.J., Doležel, J.: Genomic constitution of Festulolium cultivars released in the Czech Republic. - Plant Breed.124: 454-458, 2005.

Kopecký, D., Lukaszewski, A.J., Doležel J.: Meiotic behaviour of individual chromosomes of Festuca pratensis in tetraploid Lolium multiflorum. - Chromosome Res. 16: 987-998, 2008.

Kopecký, D., Simonikova, D., Ghesquiere, M., Dolezel, J.: Stability of genome composition and recombination between homoeologous chromosomes in Festulolium (Festuca $\times$ Lolium) cultivars. - Cytogenet. Genome Res. 151: 106-114, 2017.

Książczyk, T., Zwierzykowska, E., Molik, K., Taciak, M., Krajewski, P., Zwierzykowski, Z.: Genome-dependent chromosome dynamics in three successive generations of the allotetraploid Festuca pratensis $\times$ Lolium perenne hybrid. Protoplasma 252: 985-996, 2015. 
Macleod, C.J.A., Binley, A., Hawkins, S.L., Humphreys M.W., Turner, L.B., Whalley, W.R., Haygarth, P.M.: Genetically modified hydrographs: what can grass genetics do for temperate catchment hydrology? - Hydrol. Process 21: 2217 2221, 2007.

Majka, J., Bzdęga, K., Janiak, A., Ćwiek-Kupczyńska, H., Krajewski, P., Książczyk, T., Zwierzykowski, Z.: Cytogenetic and molecular genotyping in the allotetraploid Festuca pratensis $\times$ Lolium perenne hybrids. - BMC Genomics 20: 367, 2019.

Majka, J., Zwierzykowski, Z., Majka, M., Kosmala, A.: Karyotype reshufflings of Festuca pratensis $\times$ Lolium perenne hybrids. - Protoplasma 255: 451-458, $2018 \mathrm{a}$.

Majka, M., Serfling, A., Czembor, P.C., Ślusarkiewicz-Jarzina, A., Kwiatek, M., Ordon, F., Wisniewska, H.: Resistance of $($ Aegilops tauschii $\times$ Secale cereale $) \times$ Triticosecale hybrids to leaf rust (Puccinia triticina) determined on the macroscopic and microscopic level. - Front. Plant Sci 9: 1418, 2018b.

Morgan, W.G., King, I.P., Koch, S., Harper, J.A., Thomas, H.M.: Introgression of chromosomes of Festuca arundinacea var. glaucescens into Lolium multiflorum revealed by genomic in situ hybridisation (GISH). - Theor. appl. Genet 103: 696-701, 2001

Morgan, E., Timmerman-Vaughan, G., Conner, A., Griffin, W., Pickering, R.: Plant interspecific hybridization: outcomes and issues at the intersection of species. - Plant Breed. Rev. 34: 161-220, 2011.

Pasakinskiene, I., Anamthawat-Jónsson, K., Humphreys, M.W., Jones, R.N.: Novel diploids following chromosome elimination and somatic recombination in Lolium multiflorum $\times$ Festuca arundinacea hybrids. - Heredity 78: 464-469, 1997.

Płażek, A., Pociecha, E., Augustyniak, A., Masajada, K., Dziurka, M., Majka, J., Perlikowski, D, Pawlowicz, I., Kosmala, A.: Dissection of resistance to Microdochium nivale in Lolium multiflorum/Festuca arundinacea introgression forms. Plant Physiol. Biochem. 123: 43-53, 2018.

Pshenichnikova, T.A., Simonov, A.V., Ermaova, M.F., Chistyakova, A.K., Shchukina, L.V., Morozova, E.V.: The effects on grain endosperm structure of an introgression from Aegilops speltoides Tausch. into chromosome 5A of bread wheat. - Euphytica 175: 315-322, 2010.

Rees, H., Dale, P.J.: Chiasmata variability in Lolium and Festuca populations. - Chromosoma 47: 335-351, 1974.

Riley, R., Chapman, V.: Genetic control of the cytologically diploid behaviour of hexaploid wheat. - Nature 182: 713-715, 1958.

Sears, E.R., Okamoto, M.: Intergenomic chromosome relationships in hexaploid wheat. - In: Boyes, W. (ed.). Proceedings of the $10^{\text {th }}$ International Congress of Genetics. Pp. 258-259. Southam Printing Co., Montreal 1958.

Sharma, B.B., Kalia, P., Singh, D., Sharma, T.R.: Introgression of black rot resistance from Brassica carinata to cauliflower (Brassica oleracea botrytis Group) through embryo rescue. Front. Plant Sci 8: 1255, 2017.

Soltis, P.S., Soltis, D.E.: The role of hybridization in plant speciation. - Annu. Rev. Plant Biol. 60: 561-588, 2009.

Thomas, H., Humphreys, M.O.: Progress and potential of interspecific hybrids of Lolium and Festuca. - Agr. Sci. 117: 1-8, 1991.

Thomas, H.M., Morgan, W.G., Meredith, M.R., Humphreys, M.W., Leggett, J.M.: Identification of parental and recombined chromosomes in hybrid derivatives of Lolium multiflorum $\times$ Festuca pratensis by genomic in situ hybridization. - Theor. appl. Genet. 88: 909-913, 1994.

Trnka, M., Kersebaum, K.C., Eitzinger, J., Hayes, M., Hlavinka, P., Svoboda, M., Dubrovský, M., Semerádová, D., Wardlow, B., Pokorný, E., Možný, M., Wilhite, D., Žalud, Z.: Consequences of climate change for the soil climate in Central Europe and the central plains of the United States. Climatic Change 120: 405-418, 2013.

Van Heusden, A.W., Van Ooijen, J.W., Vrielink-Van Ginkel, R., Verbeek, W.H. J., Wietsma, W.A., Kik, C.: A genetic map of an interspecific cross in Allium based on amplified fragment length polymorphism (AFLP ${ }^{\mathrm{TM}}$ ) markers. - Theor. appl. Genet. 100: 118-126, 2000.

Zahradnicek, P., Trnka, M., Brazdil, R., Mozny, M., Stepanek, P., Hlavinka, P., Žalud, Z., Malý, A., Semerádová, D., Dobrovolný, P., Dubrovský, M., Reznícková, L.: The extreme drought episode of August 2011-May 2012 in the Czech Republic. - Int. J. Climatol. 35: 3335-3352, 2015.

Zwierzykowski, Z., Lukaszewski, A.J., Naganowska, B., Lesniewska, A.: The pattern of homoeologous recombination in triploid hybrids of Lolium multiflorum with Festuca pratensis. - Genome 42: 720-726, 1999.

Zwierzykowski, Z., Kosmala, A., Zwierzykowska, E., Jones, N., Jokś, W., Bocianowski, J.: Genome balance in six successive generations of the allotetraploid Festuca pratensis $\times$ Lolium perenne. - Theor. appl. Genet. 113: 539-547, 2006.

Zwierzykowski, Z., Książczyk, T., Taciak, M., Zwierzykowska, E., Jones, N., Kosmala, A.: Genome constitution in selected and unselected plants of $\mathrm{F}_{2}-\mathrm{F}_{4}$ generations derived from an allotetraploid Festuca pratensis $\times$ Lolium perenne hybrid. - In: Barth, S., Milbourne, D. (ed.): Breeding Strategies for Sustainable Forage and Turf Grass Improvement. Pp. 75-79. Springer, Dodrecht 2012.

Zwierzykowski, Z., Tayyar, R., Brunell, M., Lukaszewski, A.J.: Genome recombination in intergeneric hybrids between tetraploid Festuca pratensis and Lolium multiflorum. - J. Hered. 89: 324-328, 1998.

Zwierzykowski, Z., Zwierzykowska, E., Taciak, M., Jones, N., Kosmala, A., Krajewski, P.: Chromosome pairing in allotetraploid hybrids of Festuca pratensis $\times$ Lolium perenne revealed by genomic in situ hybridization (GISH). Chromosome Res. 16: 575-585, 2008.

Zwierzykowski, Z., Zwierzykowska, E., Taciak, M., Kosmala, A., Jones, R.N., Zwierzykowski, W., Książczyk, T., Zwierzykowski, Z.: Genomic structure and fertility in advanced breeding populations derived from an allotetraploid Festuca pratensis $\times$ Lolium perenne cross. - Plant Breed. 130: 476-480, 2011. 